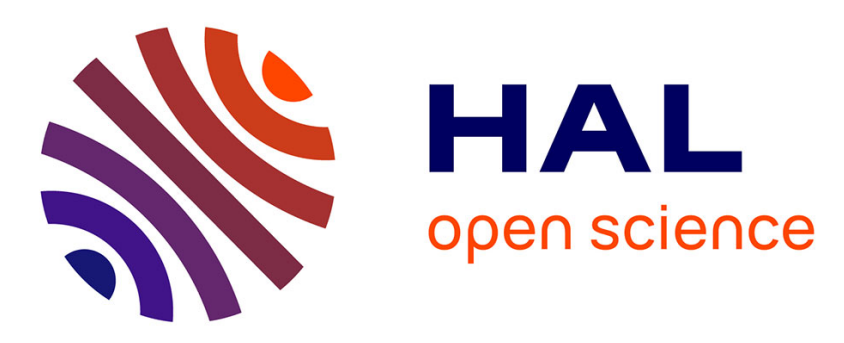

\title{
Charge recombination processes in minerals studied using optically stimulated luminescence and time-resolved exo-electrons
}

Sumiko Tsukamoto, Andrew Murray, Christina Ankjaergaard, Mayank Jain, Torben Lapp

\section{To cite this version:}

Sumiko Tsukamoto, Andrew Murray, Christina Ankjaergaard, Mayank Jain, Torben Lapp. Charge recombination processes in minerals studied using optically stimulated luminescence and time-resolved exo-electrons. Journal of Physics D: Applied Physics, 2010, 43 (32), pp.325502. 10.1088/0022$3727 / 43 / 32 / 325502$. hal-00569672

\section{HAL Id: hal-00569672 \\ https://hal.science/hal-00569672}

Submitted on 25 Feb 2011

HAL is a multi-disciplinary open access archive for the deposit and dissemination of scientific research documents, whether they are published or not. The documents may come from teaching and research institutions in France or abroad, or from public or private research centers.
L'archive ouverte pluridisciplinaire HAL, est destinée au dépôt et à la diffusion de documents scientifiques de niveau recherche, publiés ou non, émanant des établissements d'enseignement et de recherche français ou étrangers, des laboratoires publics ou privés. 


\title{
Charge Recombination Process in Minerals Studied using Optically Stimulated Luminescence and Time-resolved Exo-electrons
}

Sumiko Tsukamoto ${ }^{1,2,3}{ }^{*}$, Andrew Murray ${ }^{2}$, Christina Ankjærgaard ${ }^{3}$, Mayank Jain ${ }^{3}$, Torben Lapp $^{3}$

${ }^{1}$ Leibniz Institute for Applied Geophysics, Geochronology and Isotope Hydrology, Stilleweg 2, D-30655 Hannover, Germany

${ }^{2}$ Nordic Laboratory for Luminescence Dating, Department of Earth Sciences, Aarhus University, Risø DTU, DK-4000 Roskilde, Denmark

${ }^{3}$ Radiation Research Division, Ris $\varnothing$ National Laboratory for Sustainable Energy, Technical University of Denmark, DK-4000 Roskilde, Denmark

*Corresponding author: Sumiko.Tsukamoto@liag-hannover.de

\begin{abstract}
A time-resolved optically stimulated exo-electron (TR-OSE) measurement system has been developed using a Photon Timer attached to a gas-flow semi-proportional pancake electron detector within a Ris $\emptyset$ TL/OSL reader. The decay rate of the exo-electron emission after the stimulation pulse depends on the probability of (1) escape of electrons into the detector gas from the conduction band by overcoming the work function of the material, and (2) thermalisation of electrons in the conduction band, and subsequent re-trapping/recombination. Thus we expect the exo-electron signal to reflect the instantaneous electron concentration in the conduction band. In this study, TR-OSE and TR-OSL were measured for the first time using quartz, $\mathrm{K}$-feldspar and $\mathrm{NaCl}$ by stimulating the samples using pulsed blue LEDs at different temperatures between 50 and $250{ }^{\circ} \mathrm{C}$ after beta irradiation and preheating to $280{ }^{\circ} \mathrm{C}$. The majority of TR-OSE signals from all the samples decayed much faster than TR-OSL signals irrespective of the stimulation temperatures. This suggests that the lifetime of OSL in these dosimeters arises mainly from the relaxation of an excited state of the recombination centre, rather than from residence time of an electron in the conduction band.
\end{abstract}

Key words: optically stimulated, time-resolved, luminescence, lifetime, exo-electron, quartz, feldspar, $\mathrm{NaCl}$ 


\section{INTRODUCTION}

The luminescence lifetime of minerals has been investigated using time-resolved optically stimulated luminescence (TR-OSL) to understand the recombination process of luminescence [e.g. 1-3]. TR-OSL has been measured using pulsed laser [1, 4] or LEDs and summing signals from many pulses $[5,6]$. The time delay between stimulation and luminescence emission can be considered to result from 3 processes, see figure 1: (i) eviction of charge from the trap to the conduction band, (ii) the recombination lifetime (a function of the electron concentration in the conduction band and hole concentration) and (iii) the de-excitation time (lifetime) of the excited state of the recombination centre. As the signals here are examined after light stimulation has ceased, the first process can be neglected; the luminescence lifetime is then presumably dominated by a combination of the two latter processes, but it is difficult to determine which, if either, dominates.

One method which can be used directly to probe electron concentrations in the conduction band is the emission of optically stimulated exo-electrons (OSE). Exo-electron emission can occur when electrons in a trap absorb enough energy to overcome the work function of the crystal surface, $\chi$, and escape from the surface, or when electrons already in the conduction band acquire sufficient thermal energy to overcome the work function. By pulsing the stimulation light source and detecting both the time-resolved OSL and OSE signals between the pulses, it is possible to compare whether the lifetime of the emitted luminescence (the TROSL signal) is similar or not to the mean life of the electron concentration in the conduction band (TR-OSE signal).

Here we compare the lifetimes of these signals from quartz, $\mathrm{K}$-feldspar and $\mathrm{NaCl}$ to experimentally determine, for the first time, whether the TR-OSL lifetime is dominated by the rate at which the conduction band empties, or by the rate of relaxation of the excited state(s) of the recombination centre(s).

\section{A MODEL FOR EXO-ELECTRON EMISSION}

Here we outline the model used in this paper to describe exo-electron emission, defined as the emission of low-energy electrons from the surface of a solid following excitation by ionizing radiation. The different mechanisms of exo-electron emission from a solid have been classified according to the stimulation method by Oster et al [25] and a mathematical model was later developed by Oster and Haddad [13] to describe photo-stimulated exo-electron 
mechanisms. An overview of the different exo-mechanisms relevant to our natural dosimeters is presented in Figure 1 (solid arrows denote optical stimulation and dashed arrows denote thermal stimulation). Assuming the main dosimetric trap of the material is stable at ambient temperatures and positioned at energy E below the conduction band, and that the work function of the crystal is given by $\chi$, then five possible mechanisms for exo-electron emission can be postulated: in transition (1) the electron is released from the trap by photon absorption, but subsequent emission from the surface results from additional thermal excitation; this process is called photo-thermostimulated emission, and is discussed further in Pagonis et al [12]. In transition (2), called non-stationary photoemission, both the trap release and emission occurs in a single step induced by absorption of one photon. This mechanism is unlikely in quartz and feldspar because the blue stimulation light energy $(\sim 2.6 \mathrm{eV})$ is only just sufficient to evict the electron. In feldspar the dosimetry trap is believed to be between 2 and $2.5 \mathrm{eV}$ [23, 24] and for quartz $~ 3.0 \mathrm{eV}$ [23]. Pagonis et al. [12] derived the work function, $\chi$, for their natural quartz sample to be $\sim 1.2 \mathrm{eV}$, and the thermal assistance required to release stimulated electrons from the conduction band, W, to be $(0.29 \pm 0.02) \mathrm{eV}$, Oster and Haddad's model [13]. Other sources state the electron affinity of pure $\mathrm{SiO}_{2}$ to be between 0.9 and $1.0 \mathrm{eV}$ [26, 27]. Transition (3) represents photo-photostimulated emission in which electron release and emission results from absorption of photons, but in a two-step process. This mechanism will be further discussed in Section 7. In transition (4) the electrons are evicted by thermal energy and the subsequent exo-electron emission requires photon absorption; this is termed thermophotostimulated emission. As with transition (2), this mechanism is very unlikely in our work. If samples are first preheated to empty shallow traps, then at moderate temperatures the concentrations of thermally stimulated electrons in the conduction should be very small. In addition, after the light pulse is switched off, there are no photons available to complete the stimulation process. The final transition (5) represents the thermo-thermostimulated emission process; this is observed during TSE measurements in which there is sufficient thermal energy available at higher temperatures to first evict electrons from traps, and then to overcome the work function.. We conclude that only transitions (1) and (3) are likely to occur during timeresolved optically stimulated exo-electron emission at temperatures significantly below any prior thermal pre-treatment (preheating).

\section{PREVIOUS EXO-ELECTRON STUDIES USING NATURAL DOSIMETERS}

Ankjærgaard et al [10] developed an exo-electron measurement system attached to a Ris $\varnothing$ TL/OSL reader and were the first to measure OSL and OSE, and TL and TSE simultaneously. 
They began by comparing the dosimetric properties of surface and bulk quartz, feldspar and $\mathrm{NaCl}$, using blue light stimulation, and concluded they were indistinguishable; TL and OSL originate from whole volume of the dosimeter, whereas TSE and OSE derive from only $\sim 1$ $\mu \mathrm{m}$ below the surface. They also observed that sensitivity change (emission intensity after giving a same repeated dose and preheat) occurred only in OSL (not OSE) and as a result suggested that this sensitivity change is primarily related to changes in recombination probability. They were unable to observe IR stimulated exo-electrons from feldspar, and concluded that the electrons giving rise to the infrared stimulated luminescence signal commonly observed from feldspar do not go through the conduction band. Ankjærgaard et al [11] studied the dependence on stimulation temperature of OSL and OSE from quartz. The OSL signal monotonically decreased with increasing stimulation temperature, due to thermal quenching, but OSE increased up to $\sim 280{ }^{\circ} \mathrm{C}$ and only then decreased. They also investigated the thermal stability of OSL and OSE of quartz. The OSL signal first increased with the preheat temperatures up to $260{ }^{\circ} \mathrm{C}$ and rapidly decreased above $300{ }^{\circ} \mathrm{C}$ whereas OSE steadily decreased from $130{ }^{\circ} \mathrm{C}$. They explained this gradual decrease of OSE with stimulation temperature by a change in competition between luminescence recombination and electron ejection from the surface. Ankjærgaard et al [14] measured natural doses using OSE from 10 quartz samples and compared these equivalent doses with those obtained using OSL.

\section{INSTRUMENTATION, SAMPLES AND MEASUREMENTS}

A time-resolved exo-electron measurement system has been developed using a windowless flow-through semi-proportional pancake detector (pulse width 5-10 $\mu \mathrm{s}$ after amplification and shaping) inserted into the LED unit of a Risø TL/OSL reader [10, 11]. Pulses from the detector are time-stamped with reference to the beginning of the stimulation light pulse, using a pulse timer (15). The duration of the stimulation light pulse is referred to here as the 'ontime' and the time before commencement of the next light pulse as the 'off-time'. Electrons are emitted into a counting gas (99\% argon, $1 \%$ isobutane), multiplied and collected by the anode wire within the pancake detector. A more detailed description of the exo-electron system is given by Ankjærgaard et al [10]. The stimulation light from clusters of blue (470 $\mathrm{nm})$ or infrared $(870 \mathrm{~nm})$ LEDs penetrates the transparent plastic walls of the gas detector, and any resulting OSL is detected through a total of $7.5 \mathrm{~mm}$ Hoya U-340 glass filters by a photomultiplier tube (PMT) placed directly above the cathode grid of the gas detector. The system allows the simultaneous measurement of OSE and OSL, and can also be used to simultaneously measure thermally stimulated exo-electrons (TSE) and thermoluminescence 
(TL). We only have one pulse timer; this can be used to analyse the signals from either the gas detector or the PMT.

The OSL and OSE signals from 180-250 $\mu \mathrm{m}$ grains of quartz (WIDG8) [16] and 75 to 125 $\mu \mathrm{m}$ grains of K-feldspar (981119KF) [17] samples were measured by pressing the grains lightly into the surface of $8 \mathrm{~mm}$ diameter $(1 \mathrm{~mm}$ thick) lead discs placed in $9 \mathrm{~mm}$ stainless steel cups (Ankjærgaard et al [14] found that a lead substrate increases the intensity of the OSE signal). The OSL and OSE signals from $\mathrm{NaCl}$ were measured with grains directly placed in stainless steel cups. Eight mm diameter silver discs were used instead of lead to measure TL and TSE, because of the low melting point of lead. The samples were given a beta dose, preheated to $280^{\circ} \mathrm{C}$, cooled immediately and then the time-resolved OSL and OSE (TR-OSL and TR-OSE) signals were measured for either $200 \mathrm{~s}$ (with an on-time of $50 \mu \mathrm{s}$ and an offtime of $100 \mu \mathrm{s}$ ) or for $2000 \mathrm{~s}$ (with an on-time of $200 \mu \mathrm{s}$ and an off-time of $1.8 \mathrm{~ms}$ ) at temperatures of $50,100,150,200$ and $250{ }^{\circ} \mathrm{C}$. The preheat temperature of $280{ }^{\circ} \mathrm{C}$ was chosen to investigate the dependence of OSE and OSL on a wide range of stimulation temperatures (from 50 to $250{ }^{\circ} \mathrm{C}$ ). Different blue LED powers of $1.5,10$ and $25 \mathrm{~mW} . \mathrm{cm}^{-2}$ were used for $\mathrm{NaCl}$, quartz and $\mathrm{K}$-feldspar, , respectively. TL and TSE curves for $\mathrm{NaCl}$ and quartz were measured by heating to $400{ }^{\circ} \mathrm{C}$ at $2{ }^{\circ} \mathrm{C} / \mathrm{s}$, and for $\mathrm{K}$-feldspar to $350{ }^{\circ} \mathrm{C}$ at $5{ }^{\circ} \mathrm{C} / \mathrm{s}$. An optical attenuator made of thin card punctured with many small pinholes was inserted within the glass filter layers to reduce the signal intensity when the OSL signal approached PMT saturation $\left(>10^{6}\right.$ counts $\left.^{-1}\right)$. A similar attenuator was used to monitor the rise- and fall-times of the LED pulses.

\section{TL AND TSE SIGNALS}

TL and TSE signals from $\mathrm{NaCl}$, quartz and $\mathrm{K}$-feldspar were measured following beta doses of 100, 1000 and $1000 \mathrm{~Gy}$, respectively (Figure 2). Similar TL and TSE curves up to $250{ }^{\circ} \mathrm{C}$ were reported by Ankjærgaard et al (2006). Peaks in the TL and TSE curves from $\mathrm{NaCl}$ and quartz appear in similar positions, although the relative intensities of the peaks are very different. This suggests that the main mechanism for TL production in these peaks is electron eviction during thermal stimulation. The TL signal of K-feldspar has a single broad peak at $\sim 200^{\circ} \mathrm{C}$ but the TSE was better resolved and has peaks at 100, 150, 250 and higher than $350{ }^{\circ} \mathrm{C}$. Clearly the relationship between TL and TSE is not simple, and it can be deduced that recombination phenomena probably play a very large role in the shape of the TL curves in feldspars. This would arise, for instance, if the luminescence efficiency of electrons derived 
from a single trap varied with temperature, or if the available hole population changed significantly during the emptying of a trap.

\section{PULSED OSL AND OSE DECAY CURVES}

Pulsed OSL and OSE (POSL and POSE) stimulation curves were measured by pulsing the LEDs (using an on-time of $50 \mu \mathrm{s}$ and an off-time of $100 \mu \mathrm{s}$ ) for $180 \mathrm{~s}$ after giving the $\mathrm{NaCl}$, quartz and K-feldspar samples doses of 200, 200 and 500 Gy respectively, preheating to $280{ }^{\circ} \mathrm{C}$ and cooling immediately. The samples were then measured at temperatures of 50, 100, 150,200 and $250{ }^{\circ} \mathrm{C}$. In order to determine the intensity of any thermally stimulated signal, the recording of the signals started $8 \mathrm{~s}$ before the LEDs were switched on. Figure $3 \mathrm{a}$ and $\mathrm{b}$ show, for $\mathrm{NaCl}$, the POSL and POSE decay curves of all detected photons and electrons (i.e. for each curve, all the signal detected during both the on- and off-time of the pulsed stimulation is summed). The insets show the POSL and POSE intensities during the first $4 \mathrm{~s}$ as a function of stimulation temperature. The POSL from $\mathrm{NaCl}$ decreases towards higher temperature, whereas there was no significant temperature dependence in the POSE signal. The POSL from quartz (Fig. 3c) also decreases with temperature, especially above $150{ }^{\circ} \mathrm{C}$ (because of thermal quenching) $[16,18]$. However, the POSE from quartz increases as the temperature is increased (Fig. 3d). Thermal quenching is a recombination phenomenon, and should not therefore affect the POSE signal; the increase with temperature implies that thermal assistance plays a role at some point in the eviction process (either from the trap, or from electrons already in the conduction band). Both the POSL and POSE from K-feldspar increase with temperatures, although the POSL signal at $250^{\circ} \mathrm{C}$ then decreases (Fig. 3e, f). A strong thermally stimulated signal was observed at $250{ }^{\circ} \mathrm{C}$ for all the POSE and OSL signals (the signal recorded before the stimulation begins), suggesting that this thermal signal underlies the POSE and POSL at $250^{\circ} \mathrm{C}$.

\section{TIME-RESOLVED OSL AND OSE SIGNALS}

Figure 4 shows the time-resolved OSL and OSE (TR-OSL and TR-OSE) curves from $\mathrm{NaCl}$, quartz, and K-feldspars measured at different temperatures (the curves shown in Fig. 3 were derived from these data by integrating the signals for all the pulses during the stimulation time, for an on-time of $50 \mu \mathrm{s}$ and an off-time of $100 \mu \mathrm{s}$ ). The TR-OSL and TR-OSE off-time signals have been fitted with an equation of the form:

$$
I(t)=\sum a_{i} \cdot \exp \left[-t / \tau_{i}\right]+k \quad \text { for } \mathrm{i}=1, \ldots, \mathrm{n}
$$


where $I$ is the intensity at time $t, a_{i}$ is the intensity at $t=0$ for the ' $i$ ' th component, $\tau_{i}$ is the lifetime, $\mathrm{n}$ is the number of components, and $k$ is a constant. This fitting does not have any physical implication and should only be seen as parameterisation of the TR-OSL and TR-OSE off-time decay shapes for intercomparison of the time scales involved. It has already been argued that the behaviour of TR-OSL signals from feldspar cannot be adequately explained by an exponential model $[3,8]$ although both feldspar and quartz curves have been fitted to such models in the literature $[1-2,5,9,19-22]$.

The TR-OSL signal from $\mathrm{NaCl}$ has a constant lifetime of $\sim 30 \mu \mathrm{s}$, regardless of the temperature (Fig. 4a). The majority of the $\mathrm{NaCl}$ TR-OSE signal decays much faster than the TR-OSL but there is also a signal with a very long time constant which cannot be fitted on the measurement timescale of $100 \mu \mathrm{s}$ off-time (Fig. 4b). An average lifetime of $(0.7 \pm 0.06) \mu \mathrm{s}$ was obtained from fitting the 5 TR-OSE measurements at different stimulation temperatures (there is no detectable trend in the decay rate with stimulation temperature). The lifetime of the TR-OSL signal of quartz decreases from 37 to $5 \mu$ s with increasing temperature (Fig. 4c), as previously reported by Bailiff [19], Chithambo and Galloway [20] and Pagonis et al [21]; this is usually attributed to thermal quenching of the luminescence centre, leading to a more rapid emptying of the excited state by a non-radiative de-excitation route. The majority of the TR-OSE signal decays much faster than the TR-OSL signal ( $\tau \sim 0.6 \mu \mathrm{s} ;$ Fig. $4 \mathrm{~d}$, no trend observed with temperature). The TR-OSL signal from K-feldspar decays with apparent lifetimes of 2-3 and 20-30 $\mu$ s and the intensities decrease with increasing temperature (Fig. $4 \mathrm{e}$; the nanosecond time-scale lifetimes reported by Clark et al [1,22] and Ankjærgaard et al [3] cannot be resolved with our pulsed LEDs.) The TR-OSE signal from K-feldspar also decays much faster than the TR-OSL signal ( $\tau \sim 0.4 \mu \mathrm{s}$; Fig. 4f, no trend observed with temperature). The normalised TR-OSE signals from $\mathrm{NaCl}$, quartz and $\mathrm{K}$-feldspar during the first $11 \mu \mathrm{s}$ of the off-time are shown in Fig. 5 a-c. The lifetimes found from fitting are $(0.76 \pm$ $0.07) \mu \mathrm{s},(0.61 \pm 0.05) \mu \mathrm{s}$ and $(0.38 \pm 0.03) \mu \mathrm{s}$, respectively. The decay of the light signal from the blue LEDs is shown in Fig. 5d (measured directly through a pinhole attenuator by the photomultiplier tube). More than $60 \%$ of the LED pulse switches off with a lifetime of $\sim 70 \mathrm{~ns}$, and almost all of the remaining light with a lifetime of $\sim 1.8 \mu \mathrm{s}$. It appears that the majority of the TR-OSE signals from all 3 minerals decay about an order of magnitude more slowly than the dominant LED switching off time.

Time-resolved OSL and OSE signals were also recorded for $2000 \mathrm{~s}$ using longer on- (200 $\mu \mathrm{s})$ 
and off- $(1.8 \mathrm{~ms})$ times. The off-time signals are shown in Fig. 6. Both the TR-OSL and TROSE signals from $\mathrm{NaCl}$ have a weak slowly-decaying signal above $100{ }^{\circ} \mathrm{C}$; this signal appears to decay more rapidly at $100{ }^{\circ} \mathrm{C}$ and $250{ }^{\circ} \mathrm{C}$ (Fig. 6a, b). There is a similar slowly-decaying quartz TR-OSE signal but the decay is much less pronounced than that from $\mathrm{NaCl}$ (Fig. 6d). A much stronger signal was observed in the TR-OSE from K-feldspar on these timescales (Fig. 6f). This signal does not show any detectable decay (except possibly at $100{ }^{\circ} \mathrm{C}$ ); there is, however, a strong systematic dependence of the signal intensity on the stimulation temperature. This signal cannot arise from the isothermal decay of shallow TL traps at ambient temperature because any thermally induced signals detected in the period before the simulation light was first turned on are negligible for temperatures below $250{ }^{\circ} \mathrm{C}$ (Fig. 3f). Thus it is deduced that these OSE off-time signals from K-feldspar result from optical stimulation. It is considered most likely that this signal is related to photo-transferred TSE, i.e. thermal release of charges from shallow traps populated during optical stimulation [8].

Figure 7 presents a summary of the TR-OSL and TR-OSE lifetimes for $\mathrm{NaCl}$ and quartz, derived from fitting the data in Figs. 4 and 6 using a linear sum of exponential decays and a constant (5 parameter) model for TR-OSL and a single exponential for TR-OSE. For $\mathrm{NaCl}$, the $\sim 30 \mu$ s component in the TR-OSL does not show temperature dependence (Fig. 7a, OSL1). The decay rates of the second (slower) TR-OSL component and the slow TR-OSE component are similar and have a similar thermal dependence (Fig. 7a, OSL2 and OSE2). For quartz the lifetime of the first TR-OSL component varies with temperature as described earlier, between $\sim 37$ and $5 \mu \mathrm{s}$ (Fig 7b, OSL1). The slow TR-OSE lifetime is similar to that of the slow TROSL lifetime (0.1-1 ms; Fig. 7b, OSL2 and OSE2). Ankjærgaard and Jain [7, 8] have observed optically stimulated phosphorescence signals lasting up to $\sim 8 \mathrm{~s}$ in quartz and feldspar. They conclude that re-trapping and subsequent thermal eviction from shallow traps is most likely to give rise to such long term phosphorescence decay. In the case of quartz, a phosphorescence component with a lifetime varying from $1.4 \mathrm{~s}$ at $100{ }^{\circ} \mathrm{C}$ to $4 \mathrm{~ms}$ at $200{ }^{\circ} \mathrm{C}$ was attributed to trapping (during optical stimulation) and subsequent thermal detrapping of the $110{ }^{\circ} \mathrm{C}$ TL peak. It is likely that our slowly decaying TR-OSE signals arise because of a gradual emptying of charge into the conduction band from such shallow traps.

We suggest that the fast decay in our TR-OSE signal is related to conduction band emptying after optical stimulation, whereas the more slowly decaying TR-OSE components are probably related to the thermal emptying of shallow traps. However, there are two possible 
alternative explanations for our data: it is possible that electron stimulation is a two stage process (Transition 3 in Fig. 1) with a photon absorption stimulating an electron into the conduction band, and a subsequent absorption causing escape of this conduction band electron from the crystal. In this case the probability of electron ejection, and thereby the intensity should be proportional to the square of the stimulation power [13]. We have tested whether this model applies by repeated measurement of the OSE signal as a function of stimulation power, for a single aliquot of quartz (following a dose of $\sim 400 \mathrm{~Gy}$ and a preheat to $280{ }^{\circ} \mathrm{C}$ for 10 s). The data are shown in Figure 8; there is no suggestion of a non-linear relationship, and so we conclude there is no evidence for a two step process in the electron eviction from quartz. Similar observations were made using an aliquot of $\mathrm{NaCl}$, but signals from feldspar were too weak to measure at lower stimulation powers.

It is also possible that electrons in the conduction band thermalise very quickly (transition 1 in Fig. 1). This could lead to a rapid drop in the TR-OSE signal immediately following the stimulation pulse, followed by a slower recombination from the bottom of the conduction band without a corresponding TR-OSE signal. However, for both quartz and feldspars blue light stimulation is only just sufficient to cause detrapping; the stimulation energy $(2.6 \mathrm{eV})$ is similar to or less than the main OSL trap depth, i.e. 2-2.5 eV [23, 24] or $\sim 3 \mathrm{eV}$ [23], respectively. It thus seems likely that most optically evicted electrons are put into the conduction band at or close to the conduction band edge; electrons must then escape the crystal surface because of thermal effects, to give rise to an OSE signal. In this picture, electrons do not require to lose much, if any, energy to thermalise after first entering the conduction band. It therefore seems more likely that the fast drop in the TR-OSE signals of quartz and feldspar reflects a significant drop in the conduction band population. A lack of any systematic change in the rate of decrease of fast TR-OSE signals with stimulation temperature (figure 7) further supports this interpretation.

The fastest TR-OSL lifetimes are of the order of tens of microseconds in both quartz and $\mathrm{NaCl}$. This suggests that conduction band emptying must occur at either the same or faster timescales. Our TR-OSE data suggest thatconduction band emptying gives rise to the initial fast drop in the TR-OSE signals. Thus, the initial (but much slower) TR-OSL decay must reflect relaxation of the recombination center in quartz and $\mathrm{NaCl}$ This conclusion has important implications for the choice of parameters in the kinetic model [28] currently used to describe charge movement in quartz; published model parameters [28] predict several orders 
of magnitude slower conduction band emptying than observed here.

\section{CONCLUSION}

For the first time, we report on time-resolved exo-electron measurements during pulsed optical stimulation of luminescent phosphors. We observe very slowly- or non-decaying TROSE and TR-OSL signals from quartz, $\mathrm{K}$-feldspar and $\mathrm{NaCl}$; these signals probably arise from retrapping and subsequent decay from shallow traps. However, the majority of the TROSE signal intensity decays on timescales $<1 \mu \mathrm{s}$; for $\mathrm{NaCl}$ and quartz, this is much faster than that of the corresponding TR-OSL signals ( $40 \mu \mathrm{s})$. Thus, our data strongly suggest that the observed fast TR-OSL lifetimes in quartz and $\mathrm{NaCl}$ arise mainly from the decay of excited states of recombination centres, rather than from conduction band emptying. These observations provide clear time constraints on the rates of charge movement in these natural dosimeters and have significant implications for kinetic luminescence models.

\section{REFERENCES}

[1] Clark R J, Bailiff I A, and Tooley M J 1997 Radiat. Meas. 27 211-210

[2] Chithambo M L and Galloway R B 2001 Nucl. Instrum. Methods B 183 358-368

[3] Ankjærgaard C, Jain M, Kalchgruber R, Lapp T, Klein D, McKeever S W S, Murray A S and Morthekai P 2009a, Radiat. Meas. 44 576-581

[4] Sanderson D C W and Clark R J 1994 Radiat. Meas. 23 633-639.

[5] Chithambo M and Galloway 2000 Meas. Sci. Technol. 11 418-424

[6] Denby P M, Bøtter-Jensen L, Murray A S, Thomsen K J, and Moska P 2006 Radiat. Meas. 41 774-779

[7] Ankjærgaard C, Jain M 2010a. J. Phys. D: Appl. Phys. in print

[8] Ankjærgaard C, Jain M 2010b. J. Lumines. submitted

[9] Pagonis V, Mian S M, Chithambo M L Christensen E and Barnold C 2009 J. Phys. D: Appl. Phys. 42055407

[10] Ankjærgaard C, Murray A S, Denby P M and Bøtter-Jensen L 2006 Radiat. Meas. 41 780-786

[11] Ankjærgaard C, Denby P M, Murray A S, Jain M 2008 Radiat. Meas. 43 273-277

[12] Pagonis V, Ankjærgaard C, Murray A S, Chen R 2009 J. Lumines. 129 1003-1009

[13] Oster L and Haddad J 2003 Phys. Stat. Sol. A 196 471-476

[14] Ankjærgaard C, Murray, A S, Denby P M, Jain M 2009b Radiat. Meas. 44, 232-238 
[15] Lapp T, Jain M, Ankjærgaard C, Pirtzel L 2009. Radiat. Meas. 44 571-575

[16] Murray A S, Wintle A G 1998 Radiat. Meas. 29 65-79

[17] Tsukamoto S, Asahi K, Watanabe T, Rink W J 2002. Quat. Internat. 97/98 57-67

[18] Wintle A G 1975 Geophys. J. Royal Astronom. Soc. 41 107-113

[19] Bailiff I K 2000 Radiat. Meas. 32 401-405

[20] Chithambo M L, Galloway R B 2000 Radiat. Meas. 32 627-632.

[21] Pagonis V, Ankjærgaard C, Murray A S, Jain M, Chen R, Lawless J, Greilich S, Andersen C. 2010 J. Lumines.130 902-909

[22] Clark R J, Bailiff I K 1998 Radiat. Meas. 29 553-560

[23] Huntley D J, Short M A, Dunphy K, 1996 Can. J. Phys. 74 81-91

[24] Poolton N R J, Kars R H, Wallinga J, Bos A J J 2009. J. Phys.: Condens. Matter 485505

[25] Oster L, Yaskolko V, Haddad J 1999. Phys. Stat. Sol. (a) 174 431-439

[26] Goodman A M, O’Neill J J J 1966 J. Appl. Physics 373538

[27] Schreiber E Fitting H-J 2002124 25-37

[28] Bailey R M 2001 Radiat. Meas. 33 17-45

\section{FIGURE CAPTIONS}

Fig. 1: A band model describing the generation of exo-electrons and luminescence in wide band gap materials. Photon (full arrows) or phonon (dashed arrows) absorption gives rise to electron escape from the dosimetric trap of depth E, to the conduction band, process (i). From here the electron either undergoes recombination at the luminescence centre (process (ii)) or receives further optical or thermal energy (W) to overcome the work function, $\chi$, of the surface and escape the crystal. If the luminescence centre has an excited state, then luminescence light is emitted following de-excitation of this state to the ground state (process (iii)). Oster and Haddad [13] suggest the following mechanisms for exo-electron escape from the trap: (1) photo-thermostimulated emission, (2) non-stationary photoemission, (3) photophotostimulated emission, (4) thermo-photostimulated emission, and (5) thermothermostimulated emission. These mechanisms are discussed in the main text.

Fig. 2: TL and TSE curves from (a) NaCl, (b) quartz and (c) K-feldspar, using doses of 100, 1000 and 1000 Gy respectively.

Fig. 3: POSL and POSE decay curves from (a, b) $\mathrm{NaCl}$, (c, d) quartz and (e, f) K-feldspar for 
stimulation temperatures of 50,100,150,200 and $250{ }^{\circ} \mathrm{C}$ following doses of 200,200 and $500 \mathrm{~Gy}$, respectively, and a preheat to $280{ }^{\circ} \mathrm{C}$.

Fig. 4: Time-resolved OSL and OSE from $\mathrm{NaCl}(\mathrm{a}, \mathrm{b})$, quartz(c, d) and $\mathrm{K}$-feldspar (e, f) for stimulation temperatures of 50, 100, 150, 200 and $250{ }^{\circ} \mathrm{C}$ using pulsed LED stimulation (ontime: $50 \mu$ s, off-time: $100 \mu \mathrm{s}$ ). Doses and preheat similar to those of Fig. 3 .

Fig. 5: Time-resolved OSE off-time decay at $200{ }^{\circ} \mathrm{C}$ from $\mathrm{NaCl}$ (a), quartz (b) and $\mathrm{K}$-feldspar (c) fitted by a single exponential and a constant. (d) The off-time decay of the blue LED pulse fitted with three exponential components and a constant. The lifetimes for each fit are given in each figure (only the fastest lifetime for the LED pulse).

Fig. 6: Time-resolved OSL and OSE measured for $2000 \mathrm{~s}$ : $\mathrm{NaCl}(\mathrm{a}, \mathrm{b})$, quartz (c, d) and Kfeldspar (e, f) for stimulation temperatures of 50,100, 150, 200 and $250^{\circ} \mathrm{C}$ using on- and offtimes of $200 \mu$ s and $1.8 \mathrm{~ms}$. Doses and preheat similar to those of Fig. 3.

Fig. 7: Summary of the TR-OSL and TR-OSE lifetimes for $\mathrm{NaCl}$ (a) and quartz (b) found by fitting the curves in Figs. 4 and 6.

Fig. 8: The initial intensity of continuous wave OSE from quartz as a function of stimulation power (a background signal derived from the end of the stimulation period has been subtracted from all observations). 


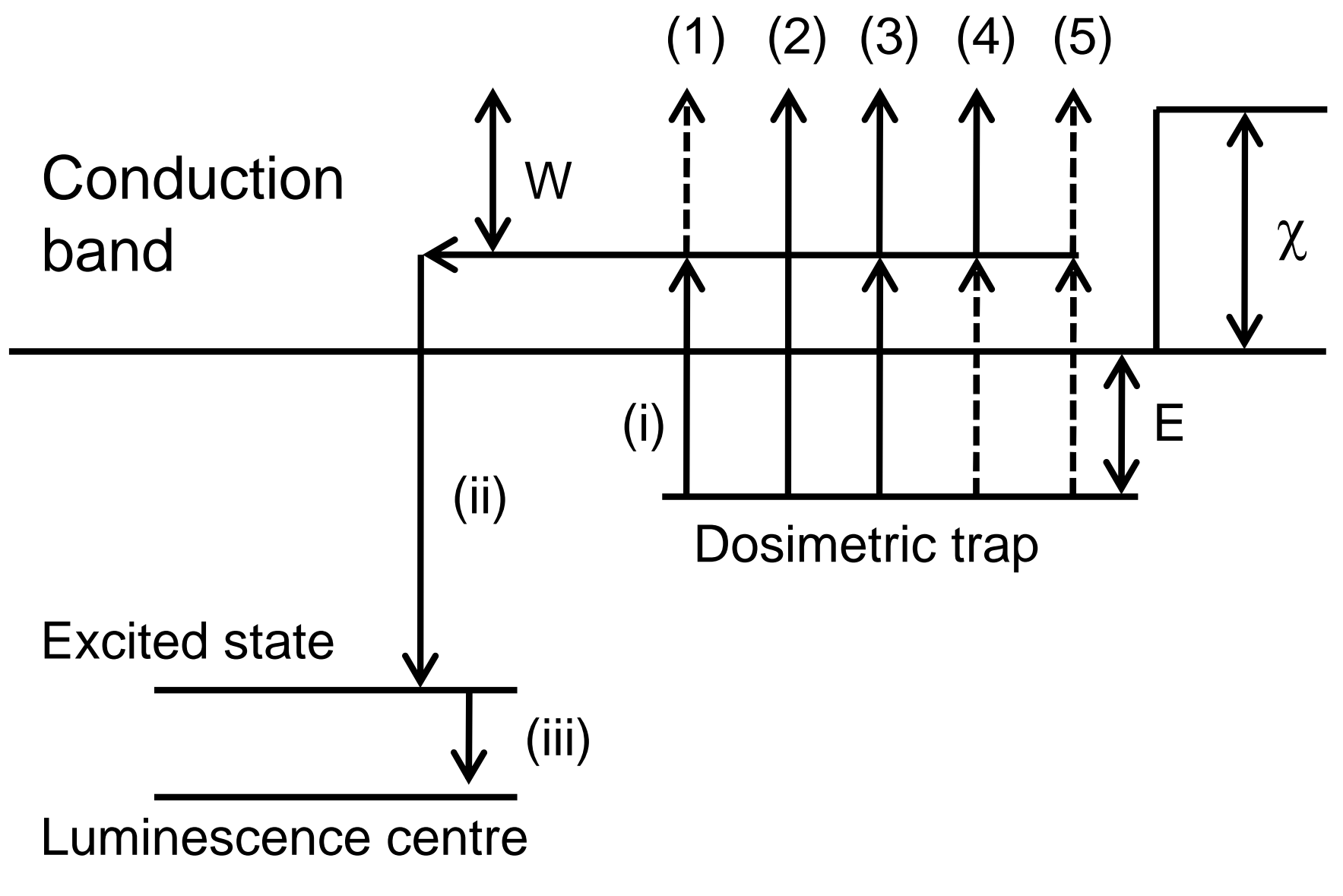

Valence band

Figure 1 (Figure 1.eps) 

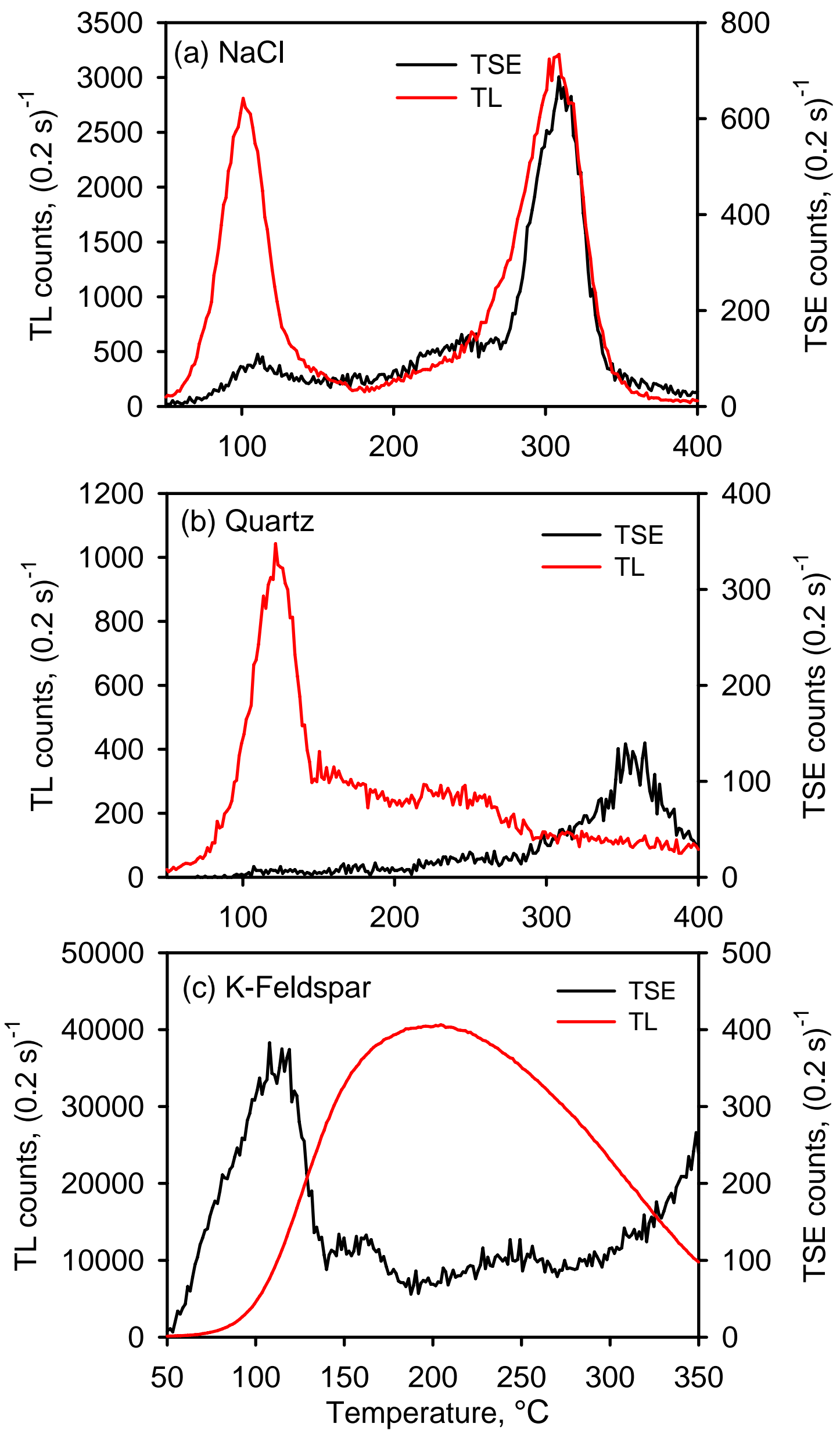

Figure 2 (Figure 2.eps) 

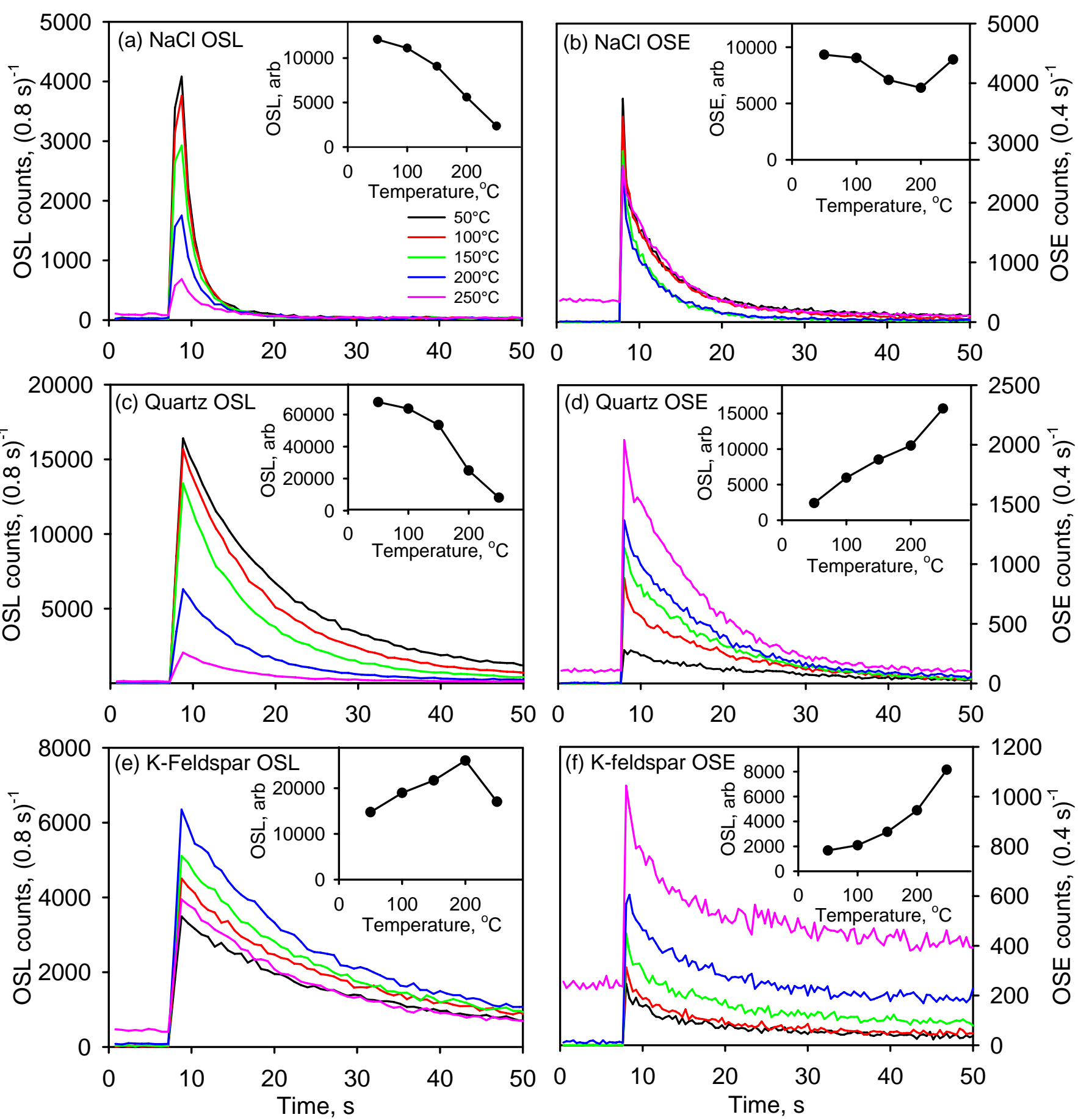

Figure 3 (Figure 3.eps) 

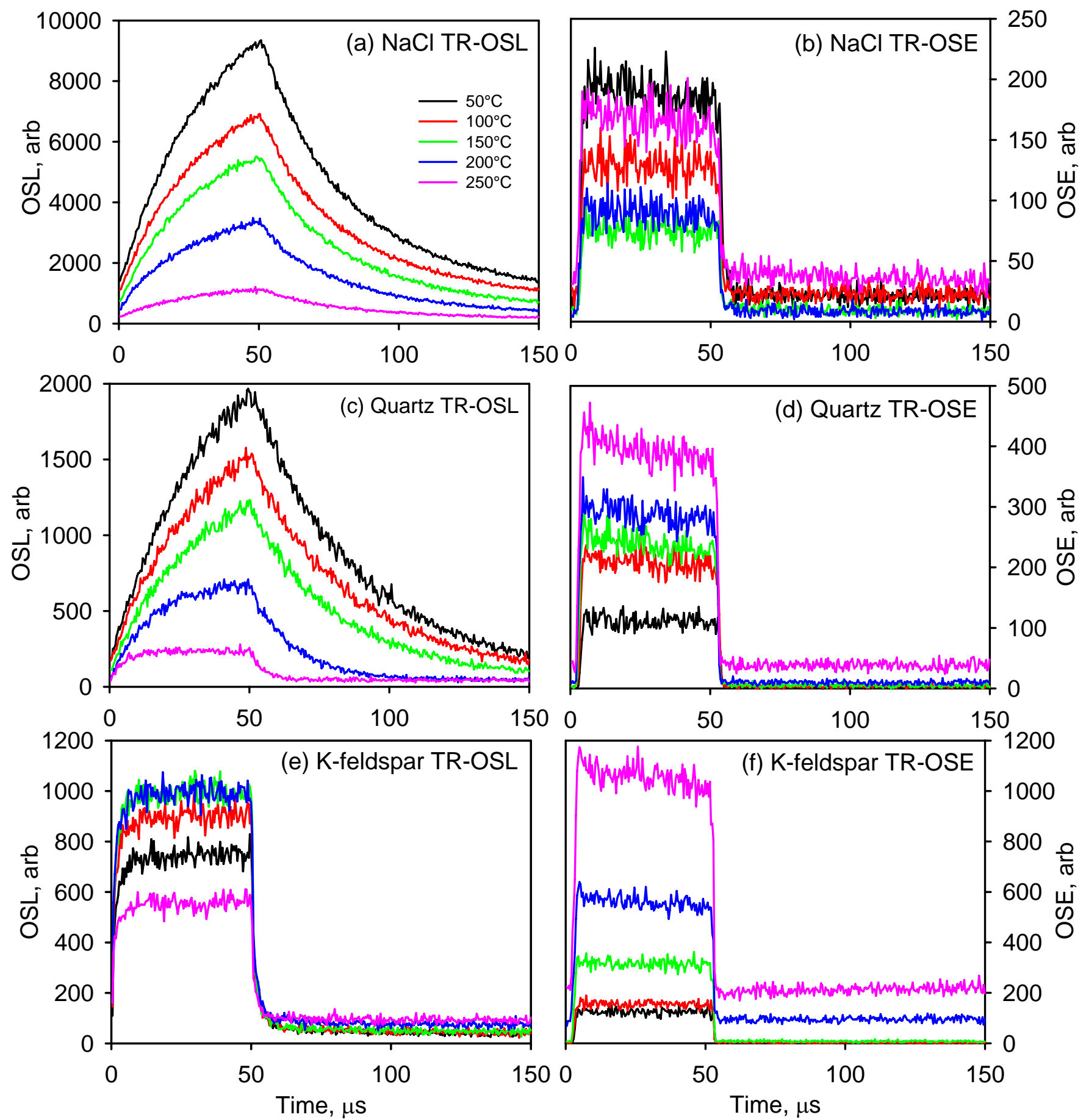

Figure 4 (Figure 4.eps) 


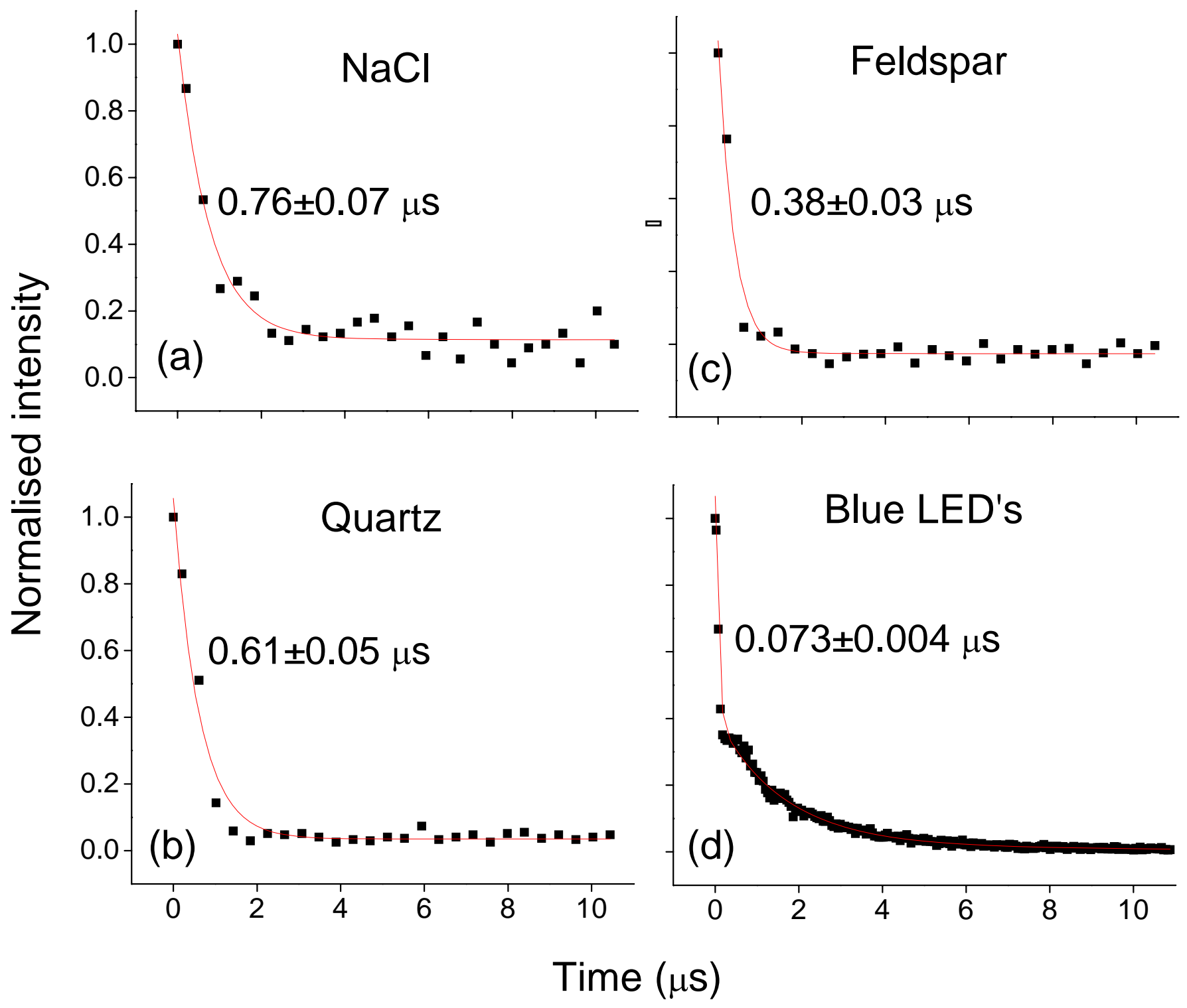

Figure 5 (Figure 5 new.eps) 

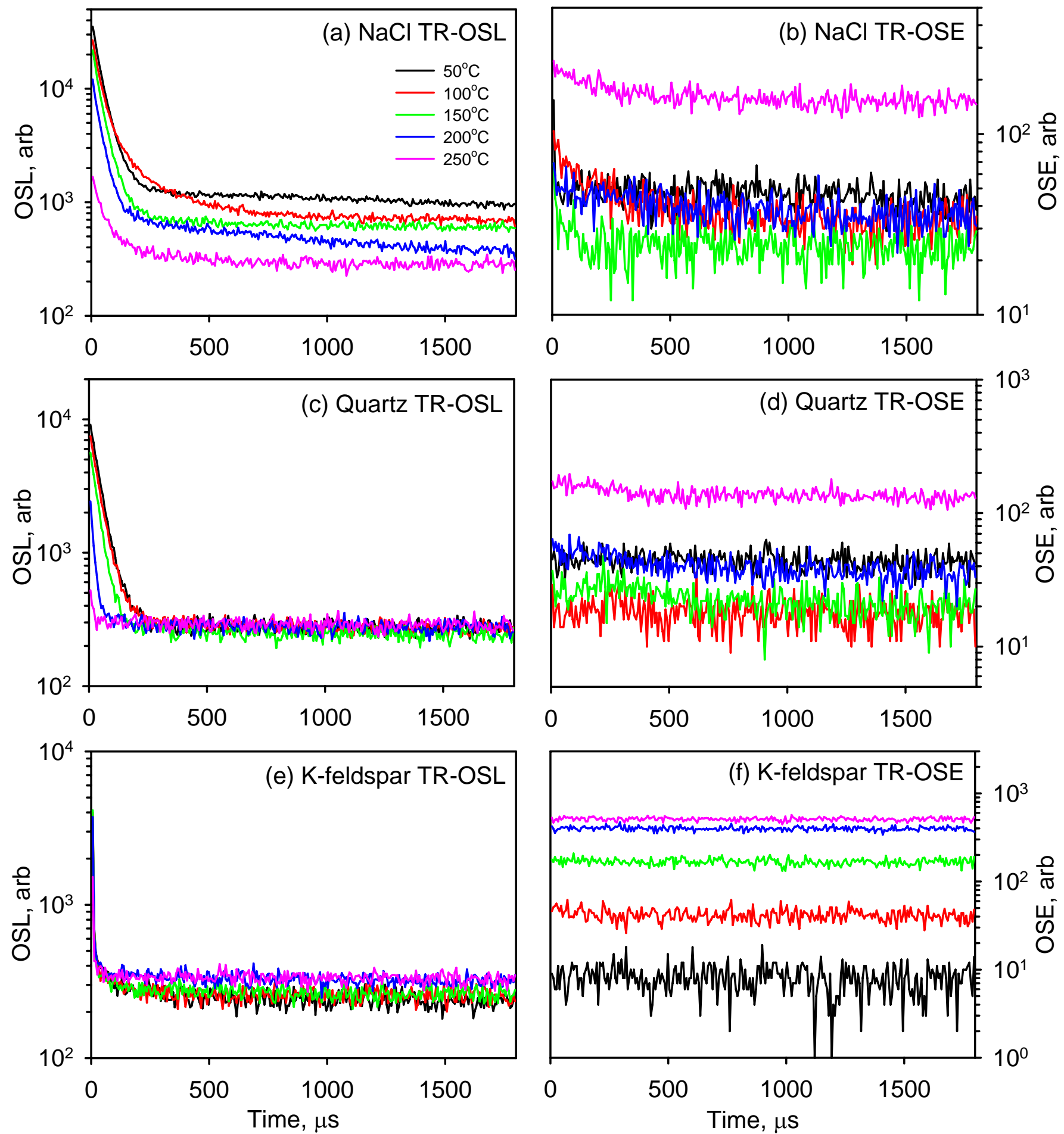

Figure 6 (Figure 6.eps) 

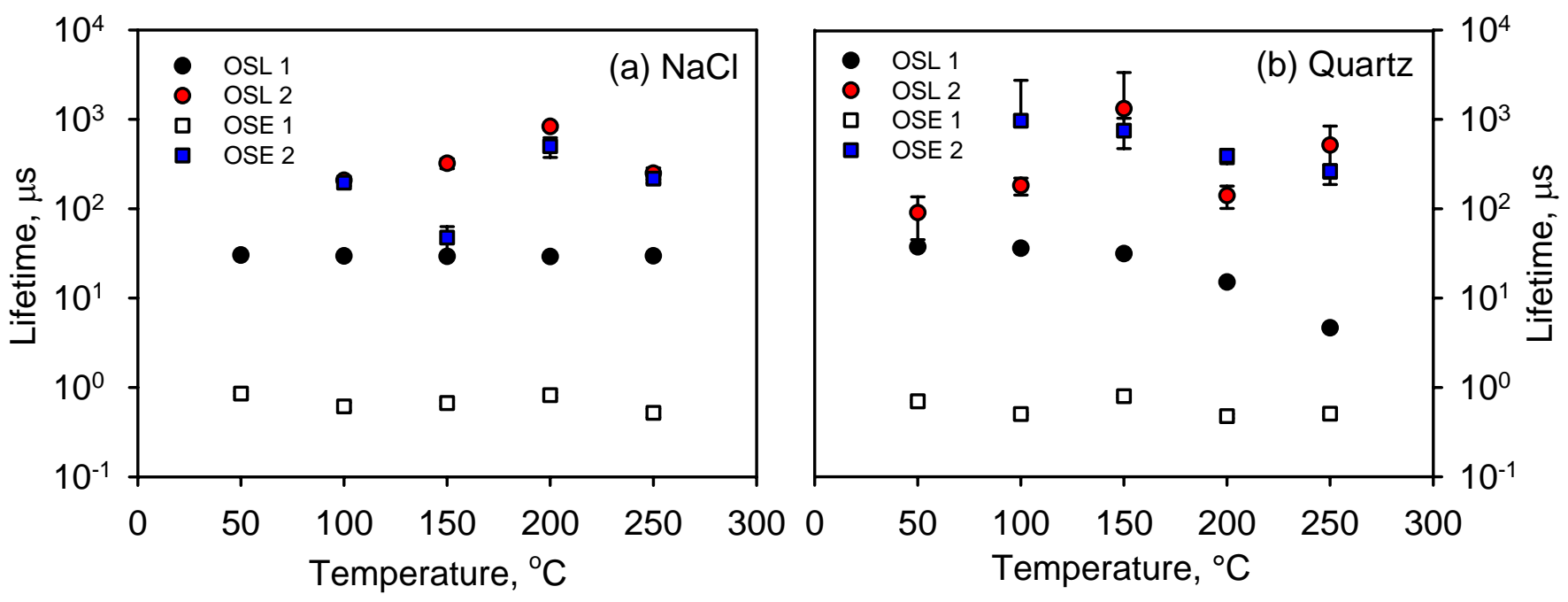

Figure 7 (Figure 7.eps) 


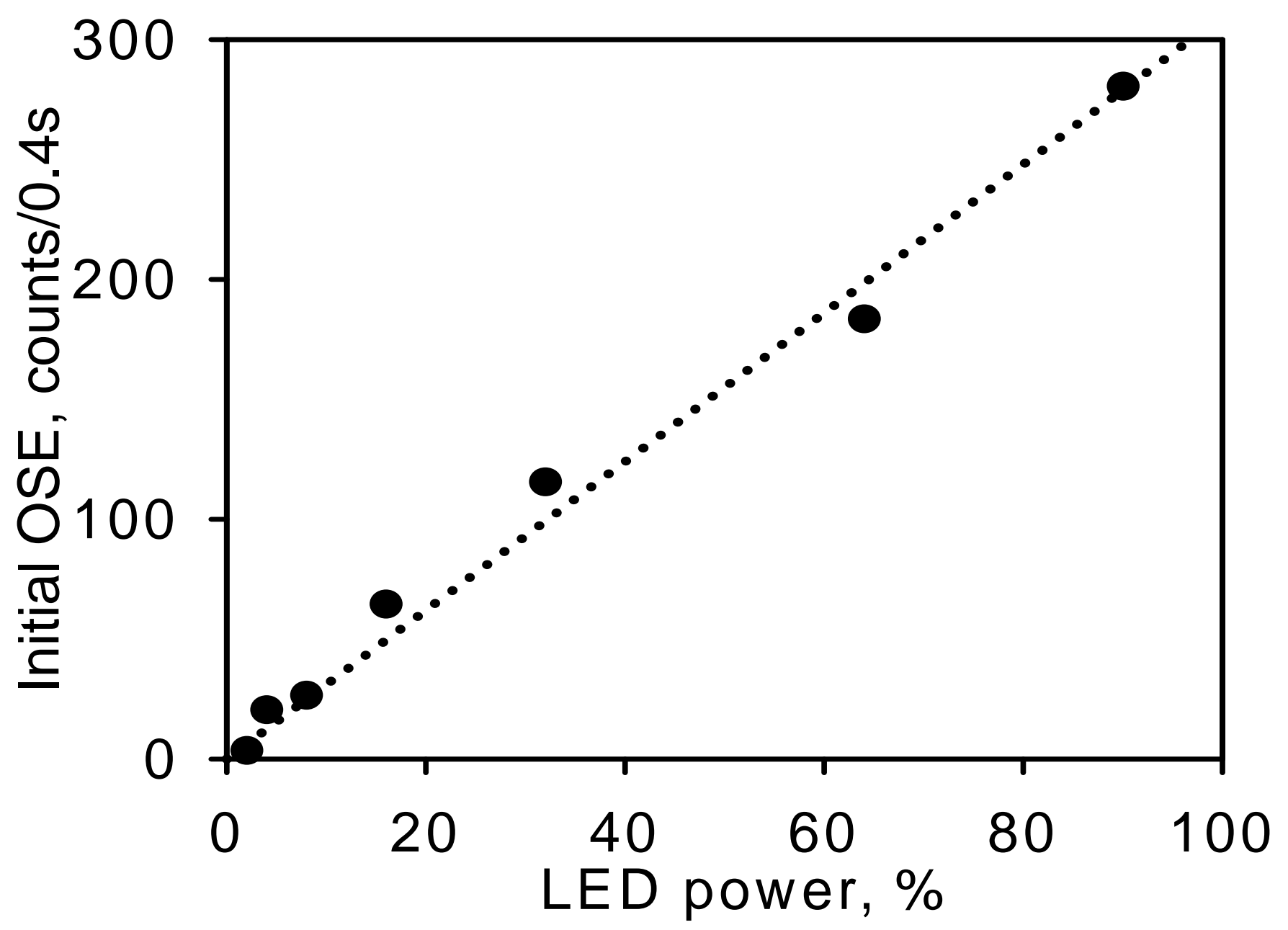

Figure 8 (Figure 8.eps) 